\title{
INVESTIGATION OF MIXED METAL SORBENT/CATALYSTS FO4 THE SIMULTANEOUS REMOVAL OF SULFUR AND NITROGEN OXIDES
}

\author{
Semi-annual Technical Report \\ Reporting Period Start Date: 4/1/98 End Date: 10/31/98 \\ Authors: \\ Dr. Ates Akyurtlu \\ Dr. Jale F. Akyurtlu \\ Report Issue Date: 10/31/98 \\ DE-FG22-96PC96216 \\ Hampton University \\ Chemical Engineering Department \\ Hampton, VA 23668
}




\section{INVESTIGATION OF MIXED METAL SORBENT/CATALYSTS FOR THE SIMULTANEOUS REMOVAL OF SULFUR AND NITROGEN OXIDES}

GRANT NUMBER: DE-FG22-96PC96216

START DATE: September 9, 1996

EXPECTED COMPLETION DATE: August 31, 1999

PRINCIPAL INVESTIGATOR: Ates Akyurtlu

CO-INVESTIGATOR: Jale F. Akyurtlu

Department of Chemical Engineering

Hampton University

Hampton, VA 23668

Semi-Annual Technical

Progress Report

October 1998 


\section{DISCLAIMER}

"This report was prepared as an account of work sponsored by an agency of the United States Government. Neither the United States Government nor any agency thereof, nor any of their employees, makes any warranty, expressed or implied, or assumes any legal liability or responsibility for the accuracy, completeness, or usefulness of any information, apparatus, product, or process disclosed, or represents that its use would not infringe privately owned rights. Reference herein to any specific commercial product, process, or service by trade name, trademark, manufacturer, or otherwise does not necessarily constitute or imply its endorsement, recommendation, or favoring by the United States Government or any agency thereof. The views and opinions of authors expressed herein do not necessarily state or reflect those of the United States Government or any agency thereof." 


\begin{abstract}
Simultaneous removal of $\mathrm{SO}_{2}$ and $\mathrm{NO}_{\mathrm{x}}$ using a regenerable solid sorbent will constitute an important improvement over the use of separate processes for the removal of these two pollutants from stack gases and possibly eliminate several shortcomings of the individual $\mathrm{SO}_{2}$ and $\mathrm{NO}_{\mathrm{x}}$ removal operations. The work done at PETC and the DOE-funded investigation of the investigators on the sulfation and regeneration of aluminasupported cerium oxide sorbents have shown that they can perform well at relatively high temperatures (823-900 K) as regenerable desulfurization sorbents. Survey of the recent literature shows that addition of copper oxide to ceria lowers the sulfation temperature of ceria down to $773 \mathrm{~K}$, sulfated ceriabased sorbents can function as selective SCR catalysts even at elevated temperatures, $\mathrm{SO}_{2}$ can be directly reduced to sulfur by $\mathrm{CO}$ on $\mathrm{CuO}$-ceria catalysts, and ceria-based catalysts may have a potential for selective catalytic reduction of $\mathrm{NO}_{\mathrm{x}}$ by methane. These observations indicate a possibility of developing a ceria-based sorbent/catalyst which can remove both $\mathrm{SO}_{2}$ and $\mathrm{NO}_{\mathrm{x}}$ from flue gases within a relatively wide temperature window, produce significant amounts of elemental sulfur during regeneration, and use methane for the selective catalytic reduction of $\mathrm{NO}_{\mathrm{x}}$.
\end{abstract}

The objective of this research is to conduct kinetic and parametric studies of the selective catalytic reduction of $\mathrm{NO}_{\mathrm{x}}$ with $\mathrm{NH}_{3}$ and $\mathrm{CH}_{4}$ over alumina-supported cerium oxide and copper oxide-cerium oxide sorbent/catalysts; investigate $\mathrm{SO}_{2}$ removal at lower temperatures by supported copper oxide-cerium oxide sorbents; and investigate the possibility of elemental sulfur production during regeneration with $\mathrm{CO}$ or with $\mathrm{CH}_{4}$ air mixtures.

The sorbents consisting of cerium oxide and copper oxide impregnated on alumina have been prepared and characterized. Their sulfation performance has been investigated in a TGA setup, studying mainly the effects of temperature and sorbent composition. The results of the sulfation experiments have been evaluated and presented in this report. A study to model the sulfation selectivity of the two constituents of the sorbents is also underway. 


\section{TABLE OF CONTENTS}

$\underline{\text { Page }}$

$\begin{array}{ll}\text { Disclaimer } & \text { ii }\end{array}$

$\begin{array}{lll}\text { Abstract } & \text { iii }\end{array}$

Executive Summary $\quad 1$

Work Done $\quad 2$

A) Sulfation 2

I) Sorbents Used 2

II) Experimental 2

III) Evaluation of Sulfation Data 3

IV) Results and Discussion $\quad 3$

V) Conclusions $\quad 6$

B) $\mathrm{NO}_{\mathrm{x}}$ Removal 6

C) Additional Activities $\quad 7$

$\begin{array}{ll}\text { Future Plans } & 7\end{array}$

References $\quad 8$

Graphs 1-12 9 


\section{EXECUTIVE SUMMARY}

This research project was proposed in response to the Program Solicitation Number DE-PS2296PC96200 for the support of advanced coal research at U.S. colleges and universities. It is related to the "Technical Topic 6. Environmental Science" cited in the program solicitation and it involves the elimination of gaseous pollutants arising from coal utilization. It is expected that this research will constitute a step in the commercial application of a new technology for the simultaneous removal of $\mathrm{SO}_{2}$ and $\mathrm{NO}_{\mathrm{x}}$.

The objective of this research project is to conduct kinetic and parametric studies of $\mathrm{SCR}$ of $\mathrm{NO}_{\mathrm{x}}$ with $\mathrm{NH}_{3}$ and $\mathrm{CH}_{4}$ over alumina-supported ceria and copper oxide-ceria sorbent/catalysts; investigate $\mathrm{SO}_{2}$ removal at lower temperatures by supported copper oxide-ceria sorbents; and investigate the possibility of elemental sulfur production during regeneration with $\mathrm{CO}$ or with $\mathrm{CH}_{4}$-air mixtures.

The expected contributions from the research are:

- Evaluation of the innovative idea of using supported ceria-based catalysts for the selective reduction of NO with methane and the determination of the kinetic parameters.

- Evaluation of the innovative idea of using methane-air mixtures for direct reduction of $\mathrm{SO}_{2}$ to selectively produce elemental sulfur and the determination of the kinetic parameters.

- Determination of the kinetic parameters for sulfation and regeneration of copper oxide-cerium oxide sorbents at temperatures below $823 \mathrm{~K}$.

The sorbents consisting of cerium oxide and copper oxide impregnated on alumina have been prepared and characterized. Their sulfation performance has been investigated in a TGA setup, studying mainly the effects of temperature and sorbent composition. The results of the sulfation experiments have been evaluated and presented in this report. A study to model the sulfation selectivity of the two constituents of the sorbents is also underway. 


\section{WORK DONE}

In this period, the main focus was on the completion of the sulfation experiments and their evaluation; the characterization of the sorbents; the completion of the construction of the experimental setup for NO-removal; and the preparation for the NO-removal experiments.

\section{A) SULFATION}

\section{I) Sorbents Used}

Table 1.Physical Properties of the Sorbents

\begin{tabular}{|l|c|c|c|c|c|}
\hline \multirow{2}{*}{ Sorbent } & \multicolumn{2}{|c|}{$\begin{array}{c}\text { Cerium Loading, } \\
\text { mass } \%\end{array}$} & \multicolumn{2}{c|}{$\begin{array}{c}\text { Copper Loading, } \\
\text { mass } \%\end{array}$} & \multirow{2}{*}{$\begin{array}{c}\text { Surface Area, } \\
\mathrm{m}^{2} / \mathrm{g}\end{array}$} \\
& Nominal & Actual & Nominal & Actual & \\
\hline SOR10-II & 5 & 4.58 & 5 & 5.54 & 122 \\
\hline SOR10-III & 2.5 & 2.26 & 7.5 & 8.42 & 134 \\
\hline SOR10-IV & 7.5 & 6.49 & 2.5 & 8 & 122 \\
\hline SOR10-V & 2 & 1.90 & 8 & 8.76 & 130 \\
\hline SOR10-VI & 0 & 0 & 10 & 10.36 & 105 \\
\hline SOR 10-VII & 10 & & 0 & 0 & 126 \\
\hline
\end{tabular}

New sorbents have been prepared with different metal loadings and support surface area. Sulfation experiments are ongoing on these sorbents. Therefore, their properties and sulfation performance will be presented in the next report.

\section{II) Experimental}

The standard procedure for running a sulfation-regeneration experiment had been described in the previous report. The sulfation experiments were performed in a CAHN instruments TG121 thermal analysis system. Reactant gas mixture was prepared from high purity bottled gases without further purification. Water and carbon dioxide were not introduced because previous work has indicated that their presence did not affect the sulfation performance of the ceria sorbents. The standard sulfation gas composition was $0.3 \% \mathrm{SO}_{2}, 3 \% \mathrm{O}_{2}$, 
and the balance $\mathrm{N}_{2}$. The gas flow rate was $200 \mathrm{~cm}^{3}(\mathrm{NPT}) / \mathrm{min}$. About $3 \mathrm{mg}$ of sorbent particles in the $75-150$ $\mu \mathrm{m}$ size range were used in each run. Under these conditions, mass transfer effects were negligible. Five sulfation-regeneration cycles were run to establish the effect of cycling. These runs were performed at $773 \mathrm{~K}$.

\section{III) Evaluation of Sulfation Data:}

The following sulfation reactions take place on the sorbents consisting of ceria and copper oxide on alumina:

$$
\begin{gathered}
\mathrm{CuO}+\mathrm{SO}_{2}+1 / 2 \mathrm{O}_{2} \rightarrow \mathrm{CuSO}_{4} \\
\mathrm{CeO}_{2}+1 \frac{1}{2} \mathrm{O}_{2}+1 / 2 \mathrm{O}_{2} \rightarrow 1 / 2 \mathrm{Ce}_{2}\left(\mathrm{SO}_{4}\right)_{3}
\end{gathered}
$$

Since the selectivity of these two reactions is not known, the following evaluation method is being used to evaluate the sulfation data:

1. Mass versus time data is obtained from the TGA results.

2. Maximum mass change $\left(\Delta \mathrm{m}_{\max }\right)$ due to the complete sulfation of copper and cerium oxides is calculated from the reaction stoichiometry of the two above-mentioned reactions and the composition and initial mass of the sorbent loaded to TGA.

3. Mass ( $\mathrm{m}$ ) versus time data during sulfation is obtained from the TGA results and $\Delta \mathrm{m}=\mathrm{m}-\mathrm{m}_{\mathrm{o}}$ is calculated at each time value. $\mathrm{m}_{\mathrm{o}}$ is the mass of the sorbent at the start of sulfation.

4. Conversion, $\mathrm{X}_{\mathrm{s}}$, defined as $\Delta \mathrm{m} / \Delta \mathrm{m}_{\max }$, is calculated for each time value and plotted as a function of time. These plots were used to compare the sorbents of different compositions and also the dependence of the performance of a sorbent on temperature.

5. The conversion data will be used to fit a reaction model with $X_{\mathrm{ce}}$ and $\mathrm{X}_{\mathrm{cu}}$ as adjustable parameters. At this time, the researchers are working on this model.

\section{IV) Results and Discussion}

The effect of temperature on the sulfation of sorbents is shown in Figures 1-6. The following observations can be made:

1. All curves exhibit two regions: 
(a) a rapid sulfation region which is generally confined to the first 600 seconds of sulfation and

(b) a slow sulfation region in which the conversion either levels off or continues at a slow and almost constant rate due to the bulk sulfation of alumina. This behavior is indicative of the significance of the bulk sulfation of alumina at $773 \mathrm{~K}$. The sulfation rate in the rapid sulfation region is not significantly affected by cycling.

2. The effect of temperature on the rate of rapid sulfation becomes more significant as the cerium content of the sorbent increases. On the other hand, the conversion at one hour of sulfation for the sorbent containing more cerium than copper by mass is about the same at all temperatures.

3. Above $773 \mathrm{~K}$, the bulk sulfation of alumina becomes significant indicated by the rate of sulfation in the slow sulfation region. At $723 \mathrm{~K}$, the bulk sulfation of alumina effectively stops after about one hour of sulfation.

4. For sorbents with high copper content, the conversion curves at different temperatures cross over as the result of the decreasing sulfur capacity of copper due to the dissociation of sulfate and increasing sulfation rate of alumina.

The effect of sorbent composition on sulfation behavior is shown at $823 \mathrm{~K}$ and $723 \mathrm{~K}$ in Figures 7 and 8, respectively. At $823 \mathrm{~K}$, the conversion in the rapid sulfation region increases with increasing cerium content up to $7.5 \%$ cerium by mass. All sorbents show the same rate in the sulfation region indicating that cerium and copper are about equally effective in facilitating the $\mathrm{SO}_{3}$ formation and hence the bulk sulfation of alumina at this temperature. The sorbent containing $7.5 \%$ cerium reaches its theoretical capacity, based on ceria and copper oxide, within about 400 seconds of sulfation while the conversion of the sorbent containing only ceria is about $80 \%$ for the same sulfation time. After one hour of sulfation, the ceria sorbent reaches a conversion of about $125 \%$. The conversion of other sorbents after one hour of sulfation depends on the cerium content, with the copper oxide sorbent giving the lowest conversion around $70 \%$ and the $7.5 \%$ cerium-containing sorbent exhibiting $120 \%$ conversion.

Curves 1 through 6 in Figure 8 show the sulfation at $723 \mathrm{~K}$ of the same sorbents as in Figure 7. Copper 
oxide and ceria sorbents show the lowest sulfur capacities at this temperature. Mixed metal oxide sorbents demonstrated much higher sulfur capacities than single oxide sorbents with the conversions at one hour of sulfation increasing with increasing ceria content up to $7.5 \%$ cerium (curve 5). The sorbent containing about equal amounts of cerium and copper has a higher sulfation rate in the rapid sulfation region but does not exhibit significant levels of bulk aluminum sulfation and, thus, the conversion levels off at about $90 \%$.

Figures 7 and 8 indicate that the best sorbent composition in the $723-823 \mathrm{~K}$ temperature range is the sorbent containing $7.5 \%$ cerium and $2.5 \%$ copper. This ratio roughly corresponds to a 1.1 molar ratio of copper and cerium and indicates that the interaction of each cerium atom with one copper atom is needed to produce the highest specific sulfur capacity.

Curves 7 and 8 in Figure 8 correspond to different total metal loadings. If curve 7, which corresponds to about $60 \%$ of monolayer coverage, is compared to curve 3 , which corresponds to a coverage of slightly above monolayer, it is seen that the specific sulfur capacity (mass of sulfur per unit mass of metal oxide) is higher for lower surface coverage as expected. Lower surface coverages provide well-dispersed metal ions and available sites for the formation of surface sulfate species (Centi, et al, 1992 a). Curve 8 is for a sorbent prepared using a higher surface area support $\left(350 \mathrm{~m}^{2} / \mathrm{g}\right)$ and has about $70 \%$ of monolayer coverage with the metal oxides. Specific sulfur capacity of this sorbent falls between the sorbent with $60 \%$ of monolayer coverage (curve 7) and the sorbent with slightly more than a monolayer coverage (curve 3). The conversion of this sorbent levels off in the slow sulfation region possibly due to pore closure and surface area loss. The results of the porosity measurements are not available yet, however, to confirm this reasoning.

The effects of cycling on the sulfation of the sorbents are presented in Figures 9-12. Conversion of sorbents containing more copper than cerium improved upon cycling, with cycle 5 giving the highest specific sulfur capacity. The sulfation capacity of sorbents containing higher amounts of cerium decreased for the second and third sulfations, then increased for the fourth sulfation cycle to settle at a conversion level slightly below the fresh sorbent. This observation is similar to the behavior of ceria sorbents reported earlier (Akyurtlu and Akyurtlu, 1995). 


\section{V) Conclusions}

The results show that in the 723 - $823 \mathrm{~K}$ temperature range combined cerium oxide-copper oxide sorbents have specific sorbent capacities (mass of sulfur removed per unit mass of metal sorbent) and sulfation rates significantly larger than those of cerium oxide or copper oxide sorbents used alone. Best sulfation performance was shown by the sorbent containing 1:1 molar ratio of cerium and copper. Specific sulfur capacities decreased as the coverage of the support surface by the metal oxides approached monolayer coverage. At $823 \mathrm{~K}$, specific sulfur capacities more than $20 \%$ over the theoretical value were obtained by sorbents with $\mathrm{Ce} / \mathrm{Cu}$ molar ratios over five sulfation-regeneration cycles without significant loss of sulfation capacity.

\section{B) NO REMOVAL}

The fixed-bed microreactor setup is ready. Some sorbents to be used in the $\mathrm{NO}_{\mathrm{x}}$ removal experiments were crushed to a particle size of 250 - $425 \mu \mathrm{m}$. One sorbent was selected for studying the extent of sulfation in a quartz microreactor. 3 grams of that sorbent was weighed and placed in the microreactor and sulfated for 2 minutes at $673 \mathrm{~K}$. This procedure was repeated on additional 3-gram samples of the same sorbent for 4 minutes at $673 \mathrm{~K}$, for 10 minutes at $673 \mathrm{~K}$, and for 10 minutes at $773 \mathrm{~K}$. These samples have been sent to a laboratory for sulfur analysis. The results of this analysis will be used to prepare sorbent/catalysts sulfated to different extents for $\mathrm{NO}_{\mathrm{x}}$ removal experiments.

\section{Experimental variables in a standard SCR experiment:}

\begin{tabular}{|c|c|c|}
\hline temperature & $=773-973 \mathrm{~K}$ & \\
\hline $\mathrm{NH}_{3} / \mathrm{NO}$ ratio & $=0.5-1.2 \quad$ or & $\mathrm{CH}_{4} / \mathrm{NO}$ ratio $=0.25-1.0$ \\
\hline concentration of $\mathrm{O}_{2}$ & $=0.5-4 \%$ & \\
\hline concentration of $\mathrm{H}_{2} \mathrm{O}$ & $=2-10 \%$ & \\
\hline concentration of $\mathrm{SO}_{2}$ & $=0-5000 \mathrm{ppm}$ & \\
\hline
\end{tabular}


C) ADDITIONAL ACTIVITIES:

1. "Behavior of Supported $\mathrm{CuO} / \mathrm{CeO}_{2}$ Sorbents under Sulfation Conditions" was presented at the ISCRE 15 Conference held at Newport Beach, CA, on September 13-16, 1998.

2. "Supported $\mathrm{CuO} / \mathrm{CeO}_{2}$ Sorbents for Gas Cleaning in Power Generation Systems"was presented at the 15th Annual International Pittsburgh Coal Conference held at Pittsburgh, PA on September 14-18, 1998.

3. An abstract, entitled "Behavior of Supported Ceria/CuO Sorbents under Sulfation Conditions" submitted to the 2nd World Congress on Environment to be held at Miami. FL in November 1998, was accepted for presentation.

4. An abstract, entitled "Supported $\mathrm{CuO} / \mathrm{CeO}_{2}$ Sorbents for Combined Removal of $\mathrm{SO}_{2}$ and $\mathrm{NO}_{\mathrm{x}}$ from Flue Gases: $\mathrm{NO}_{\mathrm{x}}$ Removal Characteristics" submitted to the AIChE Annual Meeting to be held at Miami. FL in November 1998, was accepted for presentation.

\section{FUTURE PLANS}

In the next six months, it is planned:

1. to do some more sulfation experiments, mainly the runs to investigate the effect of metal loading and support surface area;

2. to complete the characterization of all sorbents, including surface analysis by XRD by ALCOA;

3. to complete the modeling of sulfation reaction on mixed metal oxides;

4. to continue with the NO-removal experiments.

\section{REFERENCES}

1. Akyurtlu, J. F., and Akyurtlu, A. (1995), "Investigation of Combined $\mathrm{SO}_{2} / \mathrm{NO}_{\mathrm{x}}$ Removal by Ceria Sorbents", Paper presented at the Eleventh Annual Coal Preparation, Utilization, and Environmental 
Control Contractors Conference, Pittsburgh, PA July 12-14.

2. Centi, G., Passarini, N., Perathoner, S., and Riva, A. (1992), "Combined $\mathrm{DeSO}_{2} / \mathrm{DeNO}_{\mathrm{x}}$ Reactions on a Copper on Alumina Sorbent/Catalyst-1. Mechanism of $\mathrm{SO}_{2}$ Oxidation-Adsorption", Industrial and Engineering Chemistry Research, 31, 1947-1955. 
Figure 1. Effect of temperature on the sulfation of SOR10-VI $(0 \% \mathrm{Ce}, 10.36 \% \mathrm{Cu})$

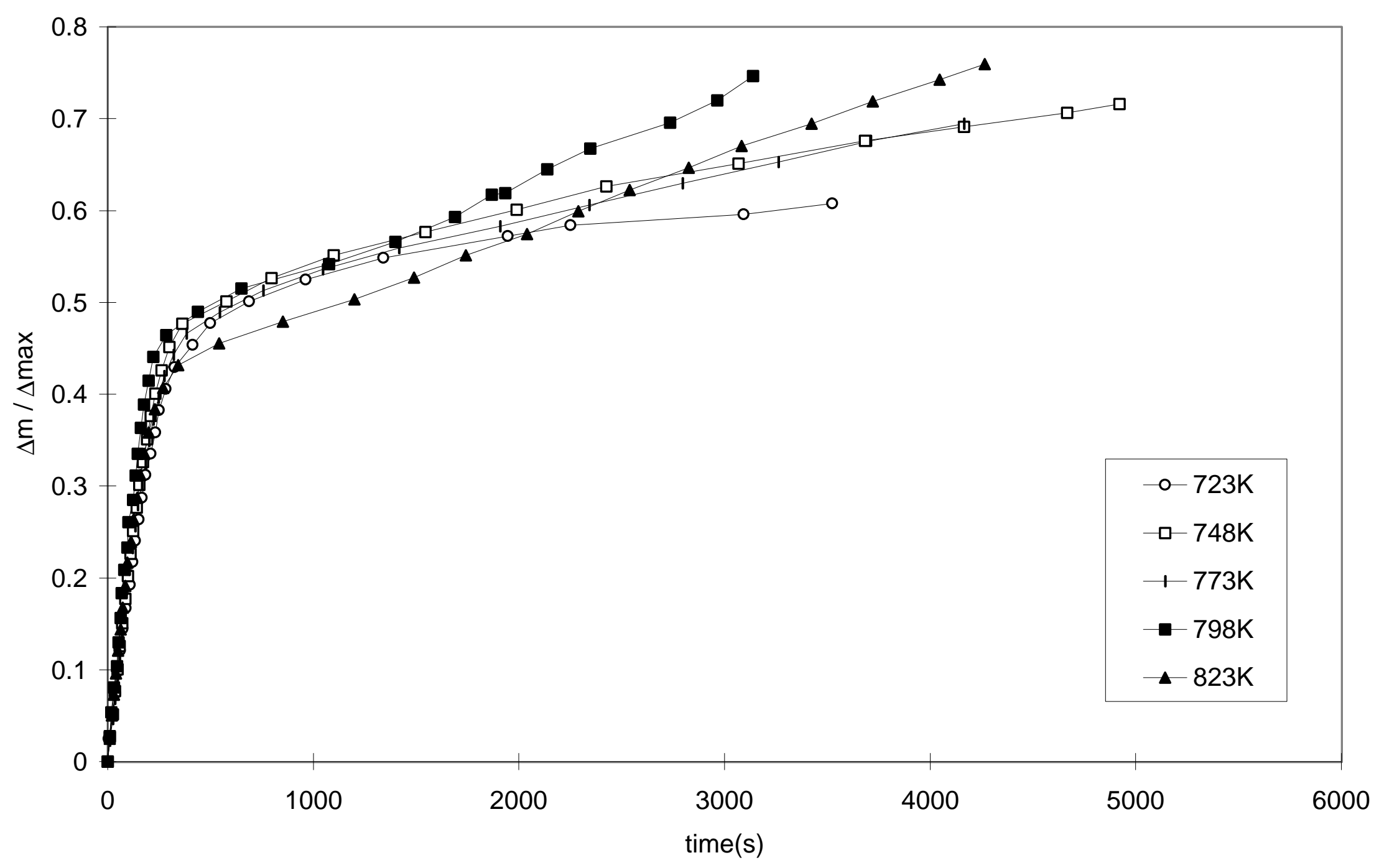


Figure 2. Effect of temperature on the sulfation of SOR10-V $(1.90 \% \mathrm{Ce}, 8.76 \% \mathrm{Cu})$

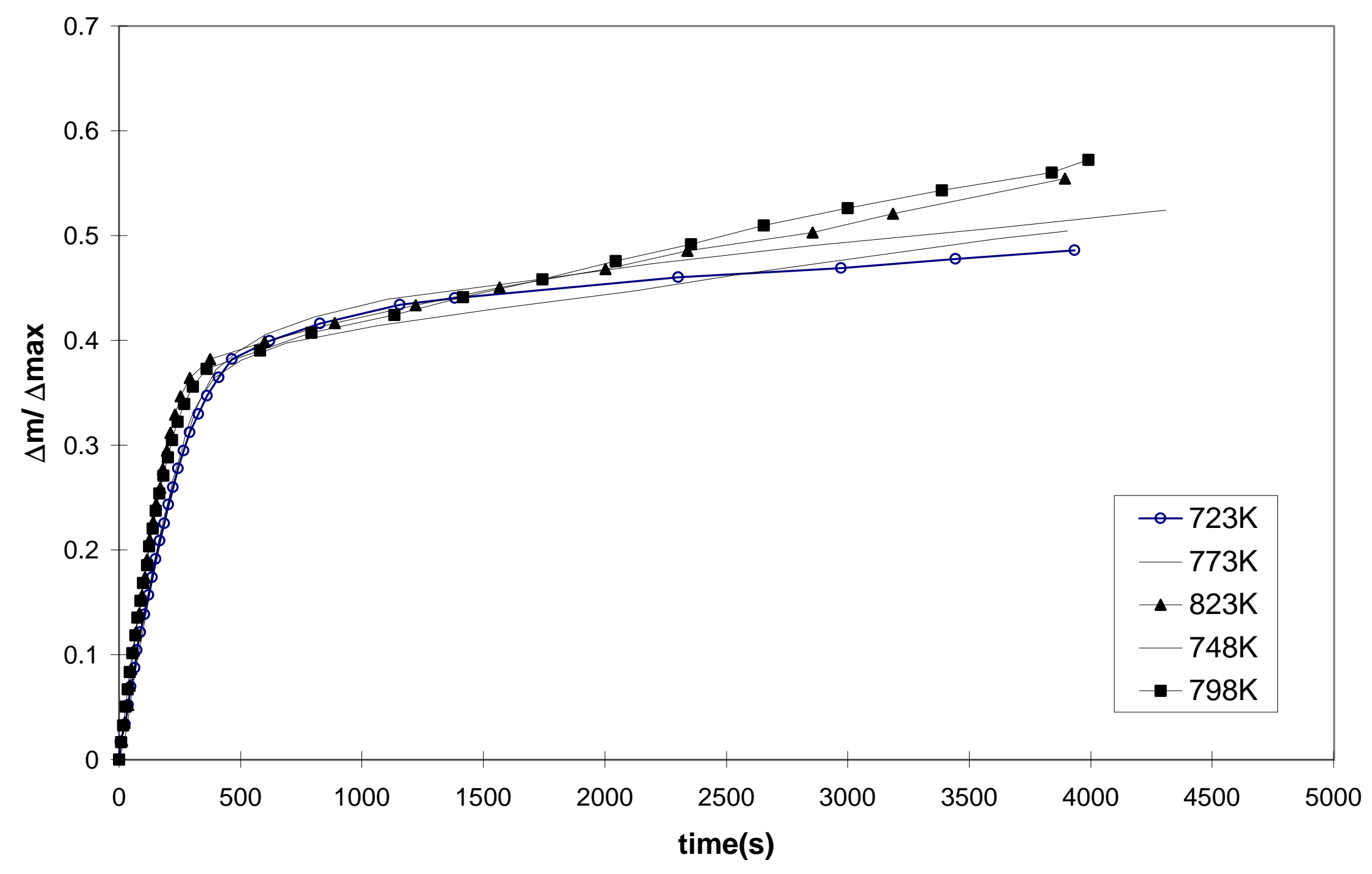


Figure 3. Effect of temperature on the sulfation of SOR10-III $(2.26 \% \mathrm{Ce}, 8.42 \% \mathrm{Cu})$

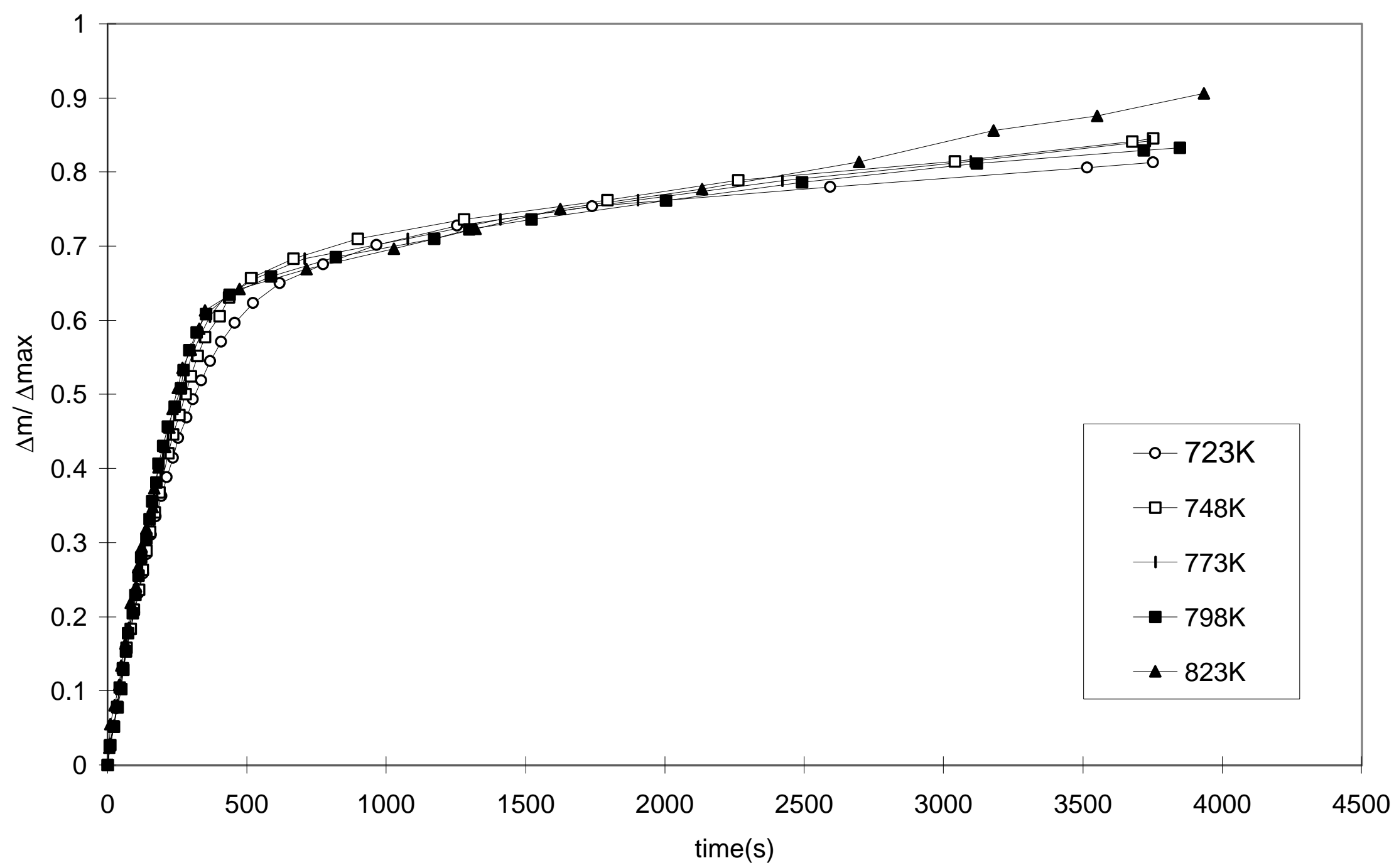




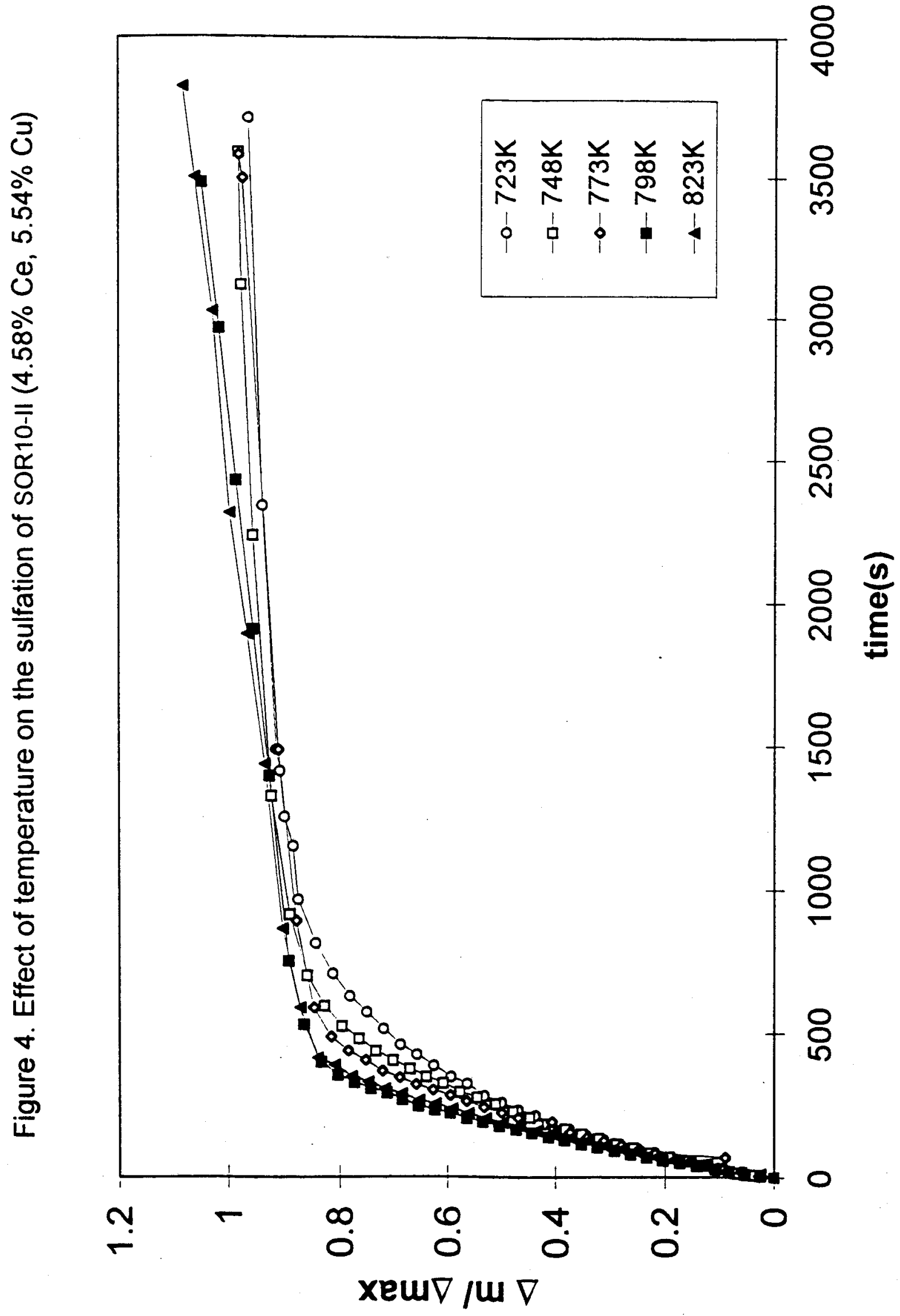


Figure 5. Effect of temperature on the sulfation of SOR10-IV $(6.49 \% \mathrm{Ce}, 2.77 \% \mathrm{Cu})$

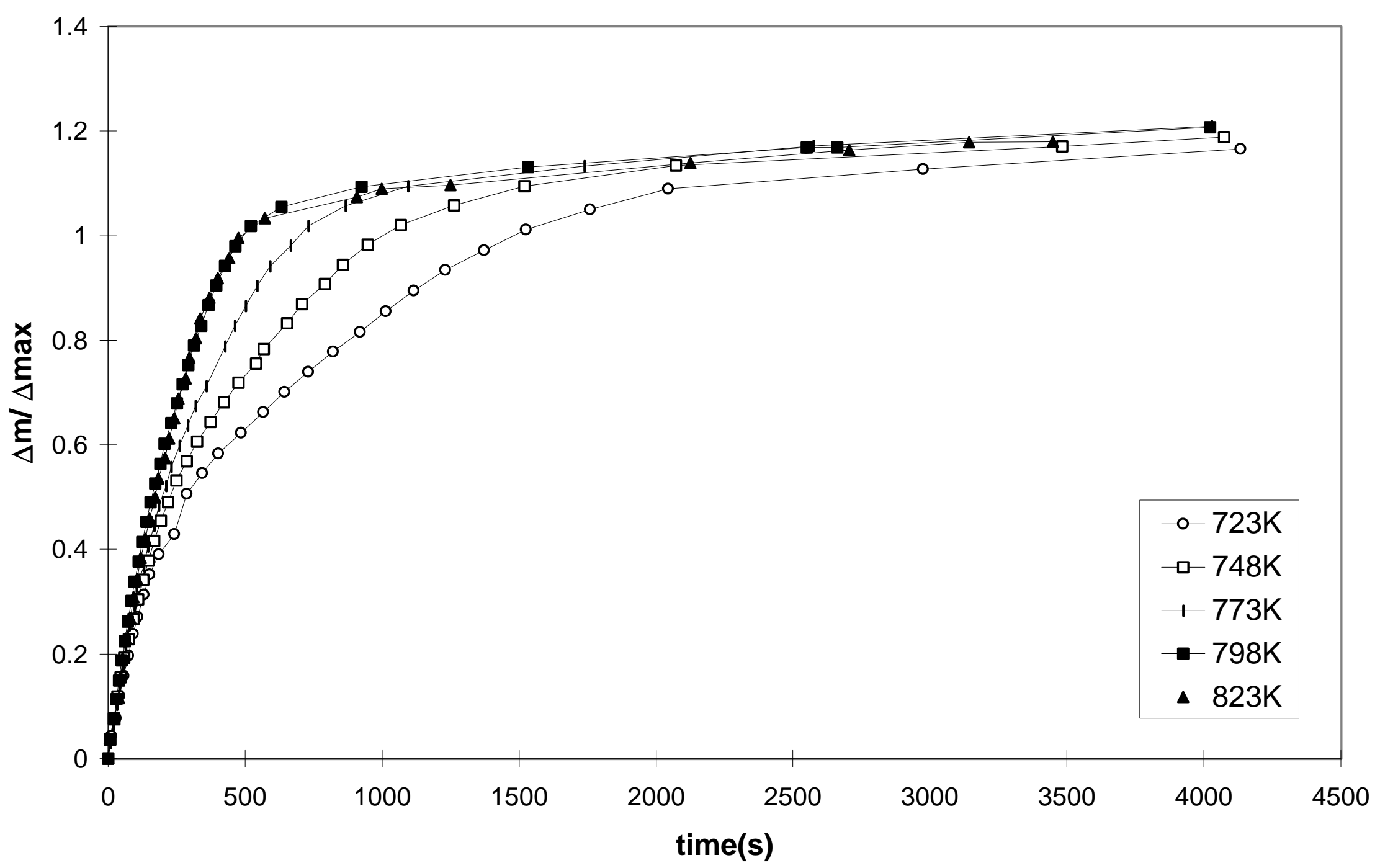


Figure 6. Effect of temperature on the sulfation of SOR10-VII $(10 \% \mathrm{Ce}, 0 \% \mathrm{Cu})$

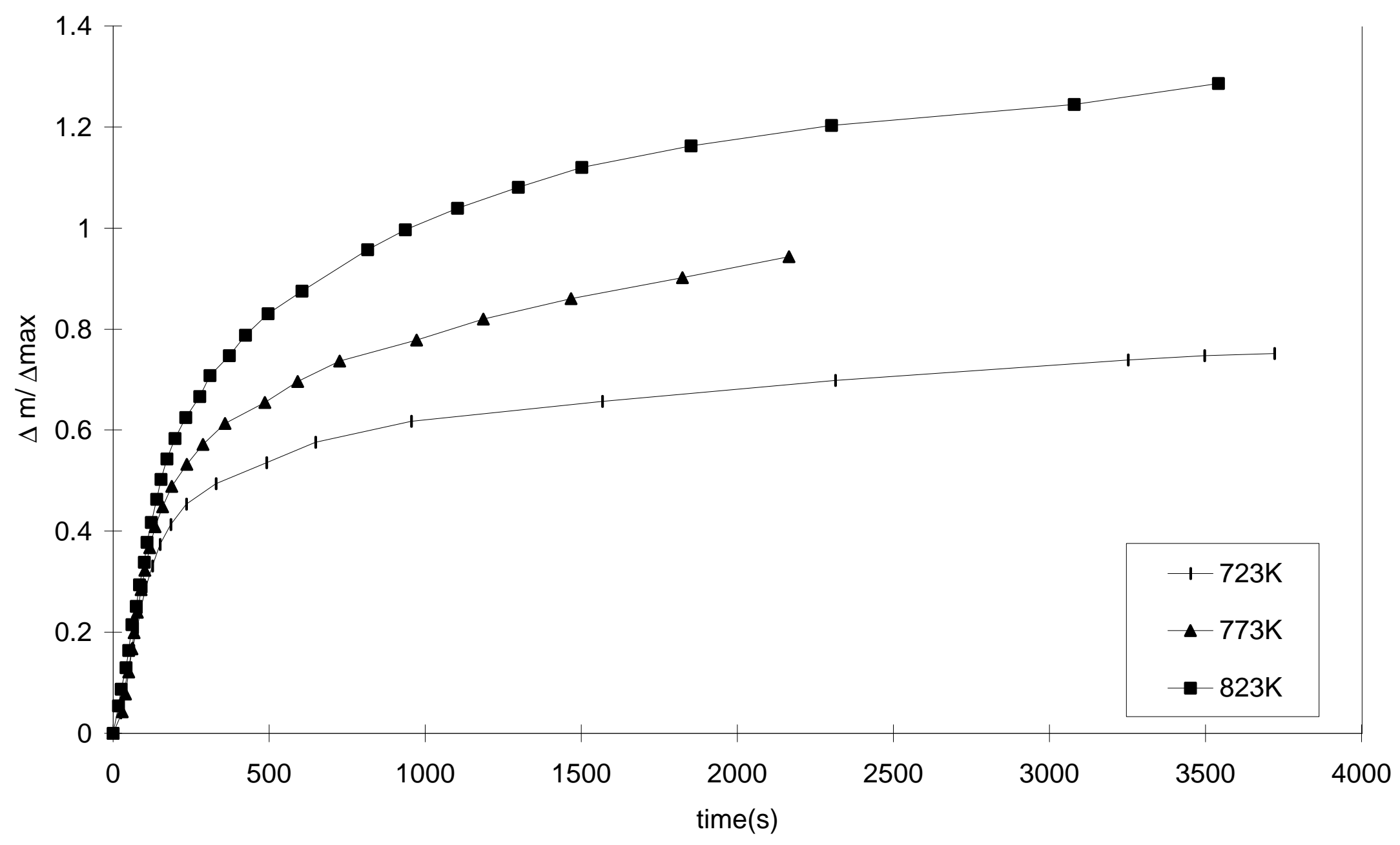




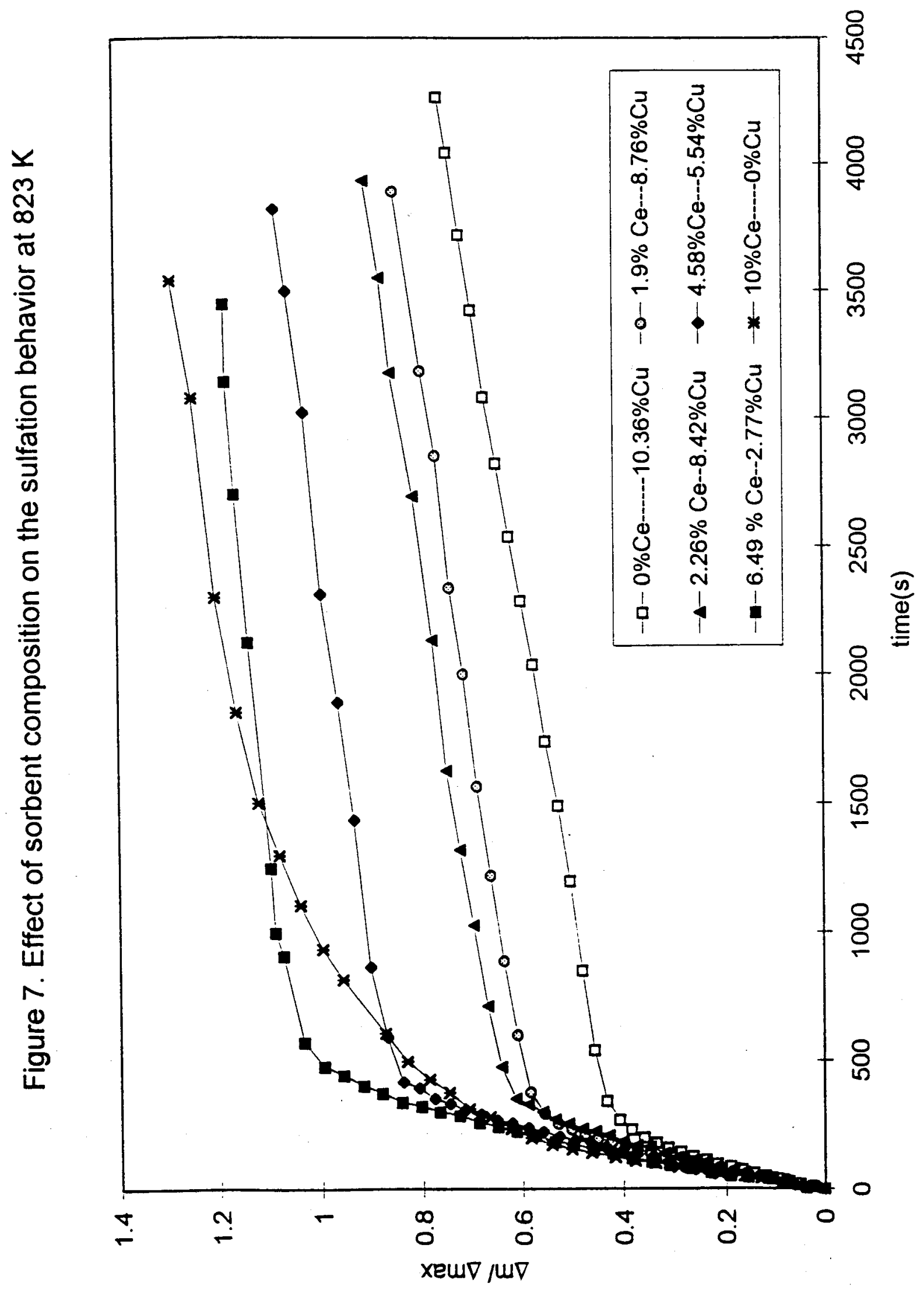




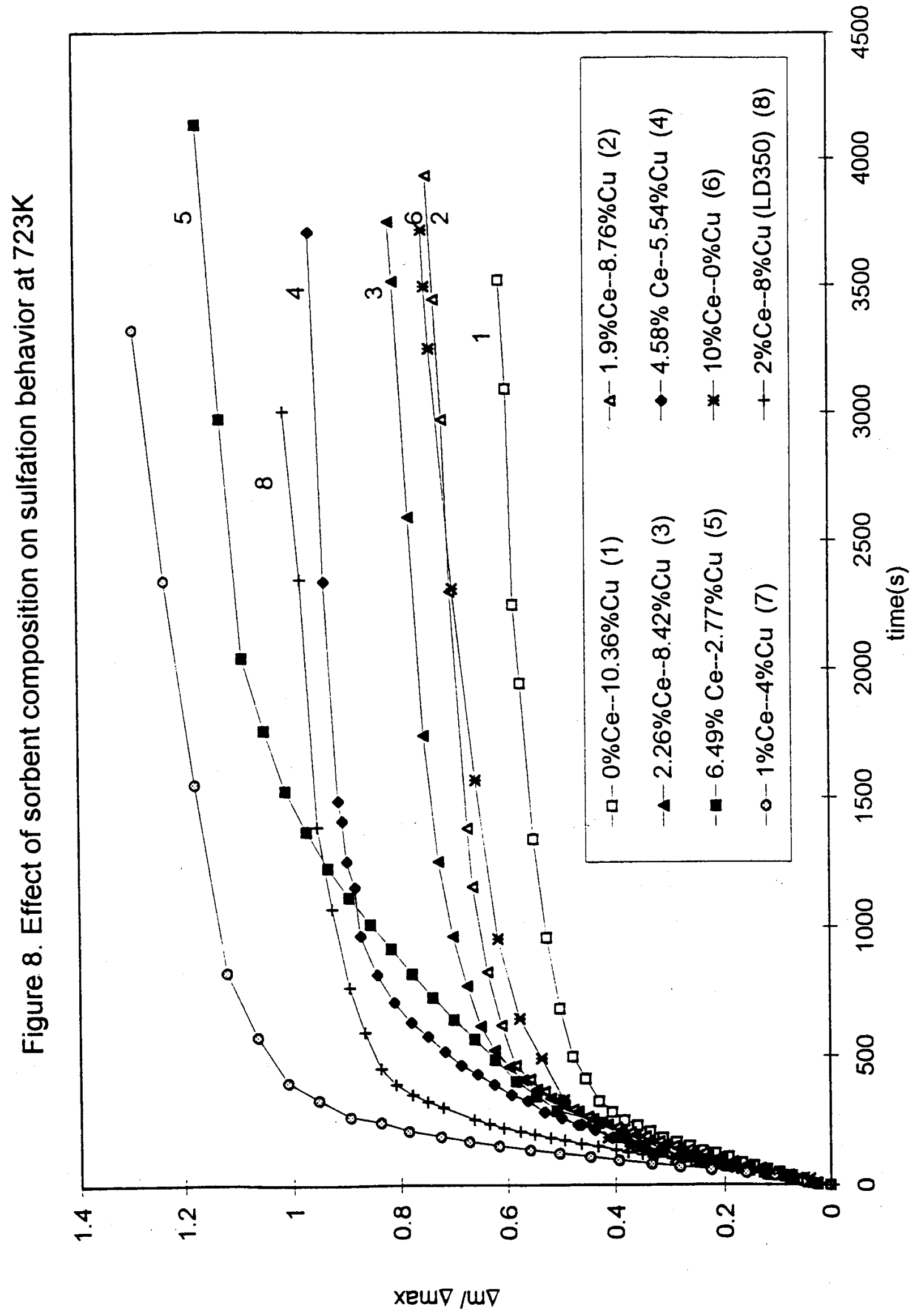


Figure 9. Cycling behavior of SOR $10-\mathrm{VI}(0 \% \mathrm{Ce}, 10.36 \% \mathrm{Cu})$ at $773 \mathrm{~K}$

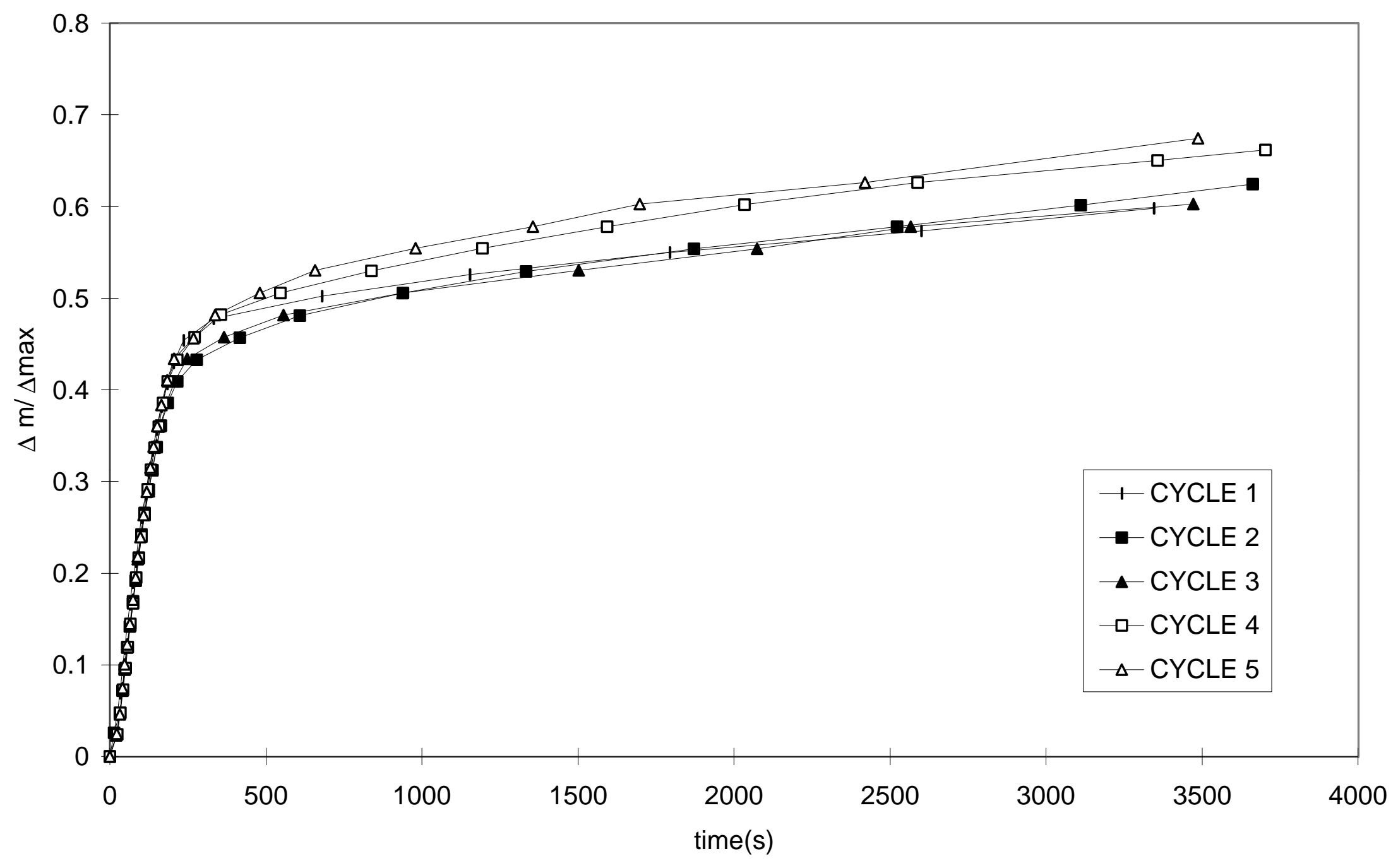


Figure 10. Cycling behavior of SOR10-V $(1.9 \% \mathrm{Ce}-8.76 \% \mathrm{Cu})$ at $773 \mathrm{~K}$

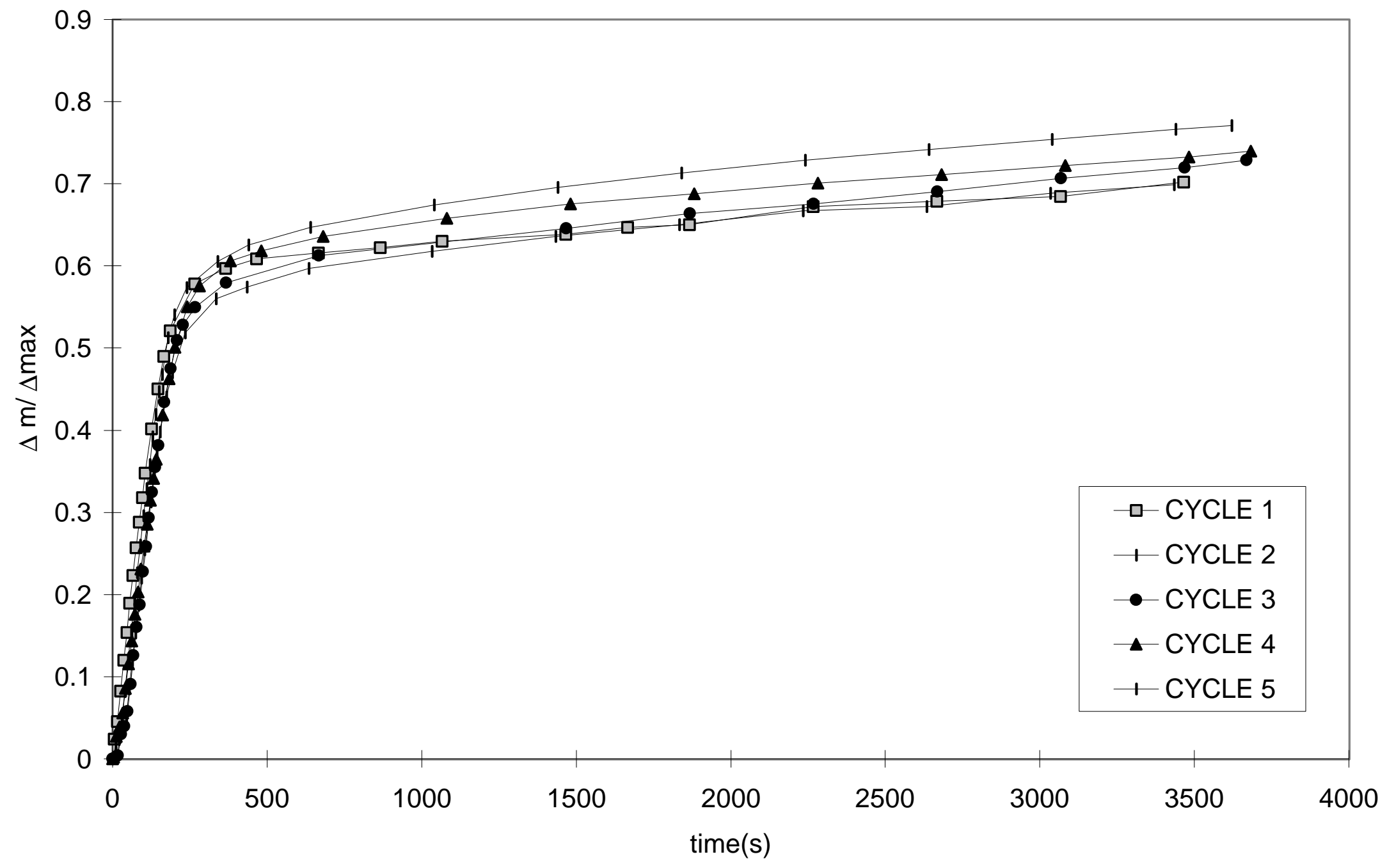


Figure11: Cycling behavior of SOR10-II (4.58\% Ce, 5.54\% Cu) at $773 \mathrm{~K}$

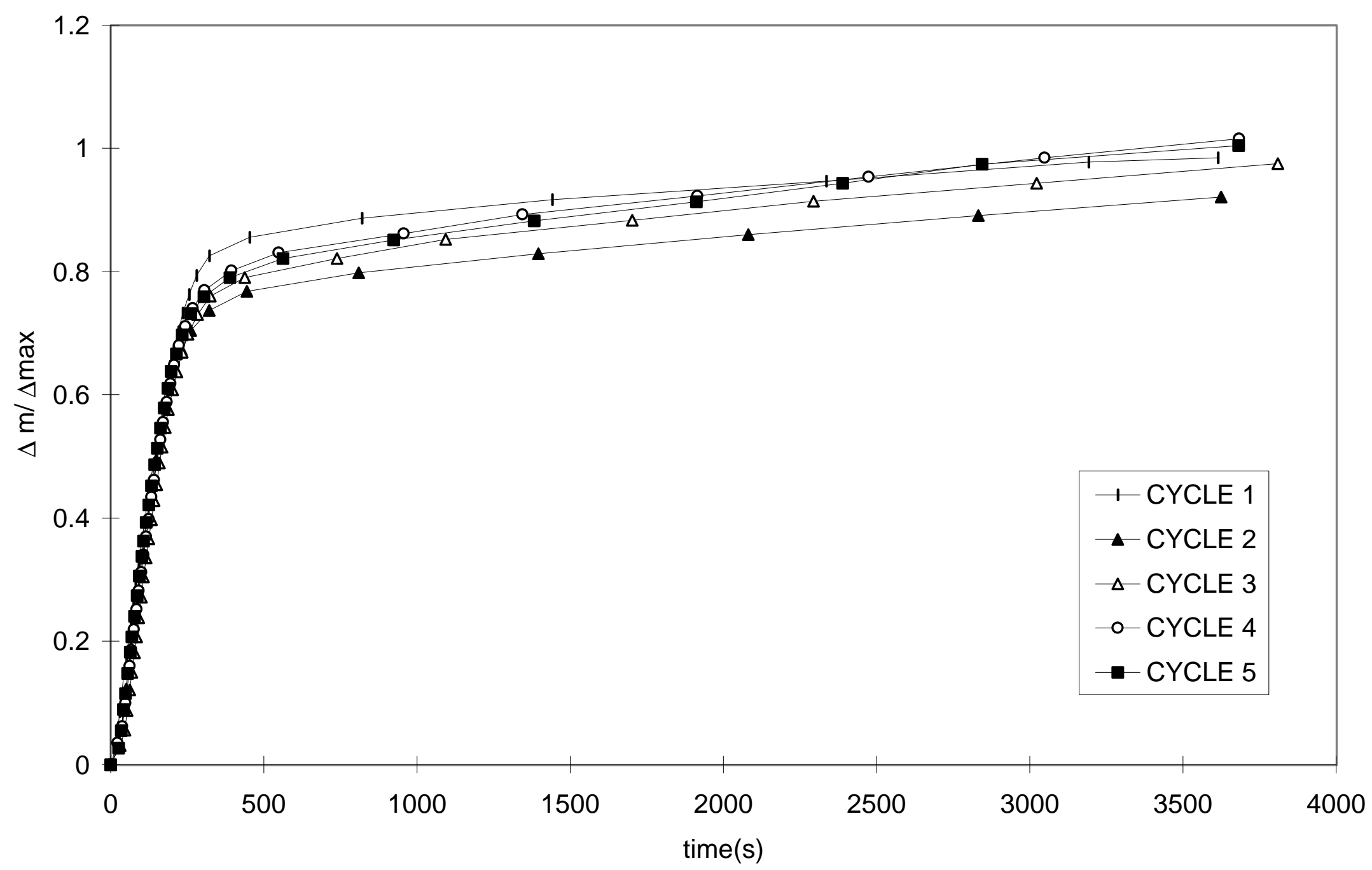


Figure 12. Cycling behavior of SOR10-IV $(6.49 \% \mathrm{Ce}, 2.77 \% \mathrm{Cu})$ at $773 \mathrm{~K}$

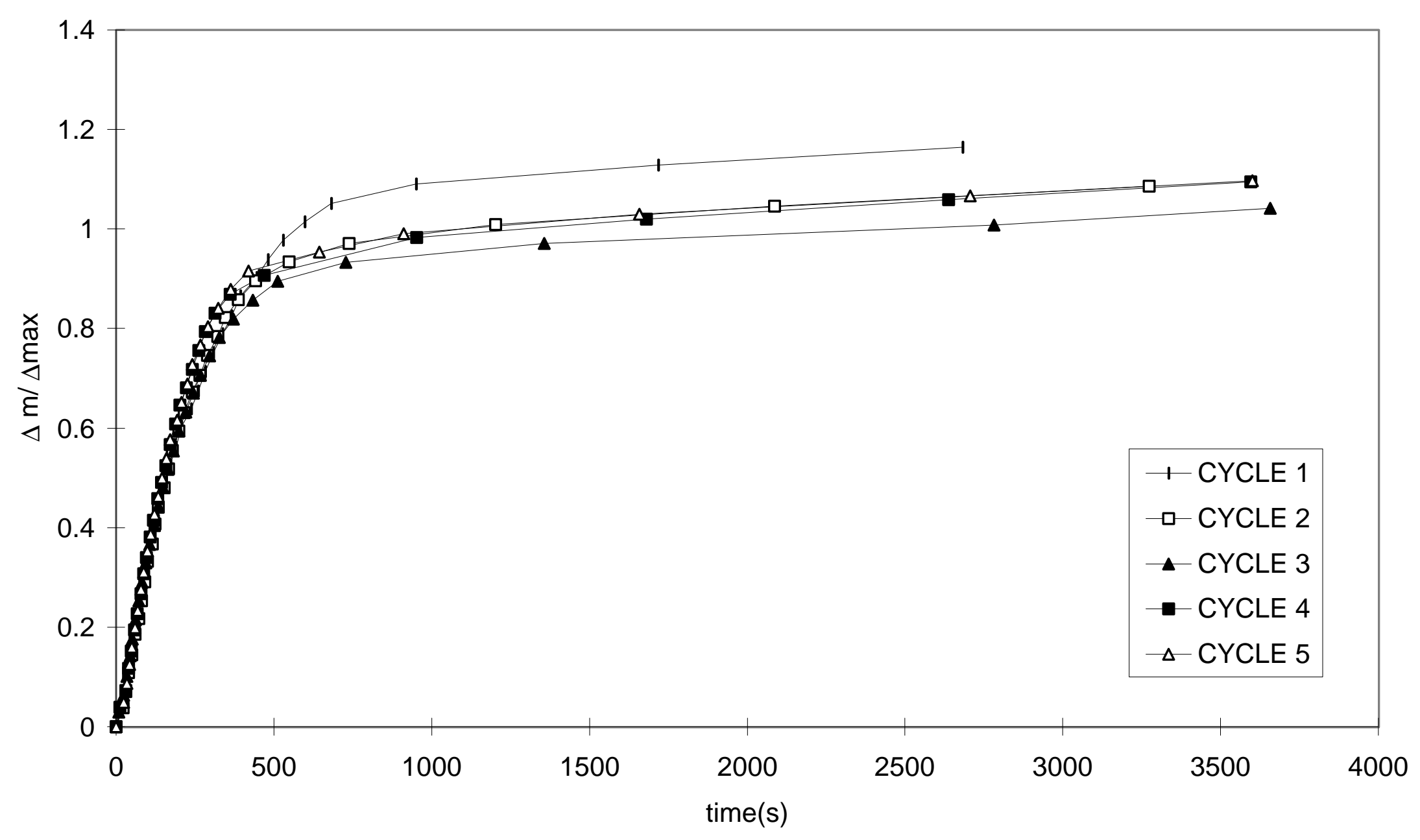

